\title{
A Rigorous Mathematical Approach to the Economic Rate of Return (ERR) and its Application to Economic Analysis
}

Fadi Asrawi ${ }^{1 *}$ and Nazim Noueihed ${ }^{2}$

${ }^{1}$ Faculty of Business Administration and Economics, Haigazian University, Lebanon

${ }^{2}$ Department of Mathematics, Division of Mathematical Sciences, Faculty of Arts \& Sciences, Haigazian University, Lebanon

\begin{abstract}
The economic rate of return (ERR) is a measure of the profitability of a revenue generating investment based on a single external discount rate which is the hurdle rate or the minimum attractive rate of return (MARR).

In this paper, we will highlight on the practical and reasonable interpretation of the (ERR) as a reinvestment rate of the present worth of costs. We shall give the usual mathematical definition of the (ERR) and derive an alternative, more useful, and applicable definition in terms of the benefit-cost ratio. We will also investigate the behavior of the (ERR) function in terms of the (MARR) as a variable. A relationship between the (ERR) and the internal rate of return (IRR) will be established. Finally, the applicability of the (ERR) method as an economic analysis method will be demonstrated.
\end{abstract}

Keywords: Investment; Hurdle rate; Present worth; Future worth; Benefit-cost ratio; Internal rate of return

Abbreviation: ERR: Economic Rate of Return; IRR: Internal Rate of Return; PWC: Present Worth of Costs; PWC: Present Worth of Costs; FWB: Future Worth of Benefits; MARR: Hurdle rate or Minimum Attractive Rate of Return

\section{Introduction}

The economic rate of return (ERR) is a rate simply calculated from the cash flow of an investment that measures the profitability of the investment. This is done by using an external rate which is the hurdle rate or the (MARR). The (ERR) is different in its interpretation than the internal rate of return (IRR). It is the equivalent rate per period at which the present worth of the investment expenditures is considered to be invested to yield a future worth equal to the future worth of the revenues invested at the (MARR) rate, while the (IRR) has no reinvestment, but a relationship exists between the two rates as we shall prove later in this paper.

\section{Literature Review}

Several financial methods are in use today when the decision maker is faced with many alternatives. These methods include present worth $(\mathrm{PW})$, annual worth $(\mathrm{AW})$, future worth $(\mathrm{FW})$, Economic rate of return (ERR), benefit -cost ratio (B/C), Internal Rate of Return (IRR) and Minimum Attractive Rate of Return (MARR). The results of these methods usually deliver reliable results to infer an optimal decision. The usages of these methods differ based on the preferences of the decisionmaker as each method has its list of advantages and disadvantages.

The Economic rate of return (ERR) and benefit-Cost ratio $(\mathrm{B} / \mathrm{C})$ are usually used as an index of profitability in making the final decision to accept or reject an investment project and are applicable only on an incremental basis. The ERR is widely accepted in the industry [1]. Using ERR allows decision makers to analyze investments in percentage ERR terms, which makes it more appealing to decision-makers. PW, FW and $\mathrm{AW}$ on the other hand can be applied to both total and incremental decisions as they use an absolute measure of investments.

The Minimum Attractive Rate of Return (MARR), which is also referred to as the hurdle rate, cutoff rate, benchmark rate, and minimum acceptable rate of return has been established for the evaluation and selection of alternatives. If a project is not expected to return at least the MARR, then the project is not worth considering. The cost of the needed capital funds has a major influence on the size of MARR, which will heavily impact the investment decision.

The IRR usage could cause many interpretational and operational problems. If the goal is to rank competing mutually exclusive alternatives, using the IRR of projects or their financial alternatives, is, generally, conceptually unsound, using the NPV, or any NPV compatible evaluation criterion including the IRR is a better approach for ranking [2].

When a project produces multiple IRRs within the economically meaningful range $(-100 \%,+\infty)$ of the discrete interest rate, it would be hard to interpret the results meaningfully. Research has shown that the IRR defines the ROR on the investment unrecovered balance and not the ROR on the whole project investment $[3,4]$.

Several ROR indices have been proposed to reflect a project's TRR that avoids the interpretational and operational problems caused by the IRR. One of them, the ERR an NPV-compatible IRR substitute (White, Case, and Agee, 1976), was chosen to demonstrate its similar applications to the IRR.

The Modified Rate of Return (MROR) was explained from different perspectives by different authors. The major difficulty encountered with the ROR method is the occurrence of MROR. ROR is the interest rate charged on the unrecovered project balance of the investment which will be zero when the project terminates $[5,6]$. The problem encountered with this definition is due to the fact that projects' cash flows are rarely based on an agreed upon interest rate but rather upon feasibility studies and future expectations or contracts. It is well known

${ }^{*}$ Corresponding author: Fadi Asrawi, Faculty of Business Administration and Economics, Haigazian University, Mexique Street, Kantari, Beirut, Lebanon, Tel: 961-11349230; E-mail: fadi.asrawi@haigazian.edu.lb

Received September 18, 2017; Accepted October 16, 2017; Published September 23, 2017

Citation: Asrawi F, Noueihed N (2017) A Rigorous Mathematical Approach to the Economic Rate of Return (ERR) and its Application to Economic Analysis. Ind Eng Manage 6: 227. doi:10.4172/2169-0316.1000227

Copyright: (C) 2017 Asrawi F, et al. This is an open-access article distributed under the terms of the Creative Commons Attribution License, which permits unrestricted use, distribution, and reproduction in any medium, provided the original author and source are credited. 
Citation: Asrawi F, Noueihed N (2017) A Rigorous Mathematical Approach to the Economic Rate of Return (ERR) and its Application to Economic Analysis. Ind Eng Manage 6: 227. doi:10.4172/2169-0316.1000227

that cash flows may reverse signs, which explains the possibility that MROR might exist. However, none of the MROR should be considered a suitable measure for the ROR [7]. Several authors have indicated the problems associated with using MROR for decision making purposes. None may be correct [1,8], It may be difficult to use in concrete decision making [9]. It fails to provide an appropriate measure of profitability for an investment project [5]. Its practical use is controversial [10], create strong shortcomings [11], arbitrary [12], and there is no coherent way for adjudicating which of them is most appropriate for determining economic attractiveness [13].

The ERR approach remedies many of the problems associated with the IRR. It utilizes the concepts of economic returns and depreciation, the principle period measure with the premium or discount in the first period based on the bid price for the investment project. This is both consistent and complementing to the MIRR and the NPV criteria.. It is also a form of the AIRR based on a geometric mean.

\section{Definitions}

\section{Mathematical definition of the ERR}

Consider an investment with a duration time of $\mathrm{n}$ periods. Let $\left(\mathrm{C}_{0}\right.$, $\left.C_{1}, C_{2}, \ldots, C_{n}\right)$ be the cost flow stream, and $\left(b_{1}, b_{2}, \ldots, b_{n}\right)$ be its revenue flow stream.

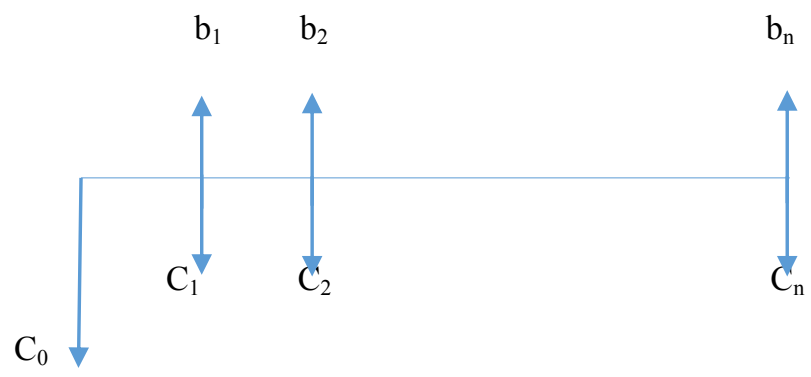

Using the MARR as a discount rate, we calculate the present worth of costs; PWC, and the future worth of benefits: PWB.

Now we consider the two-flow cash flow:

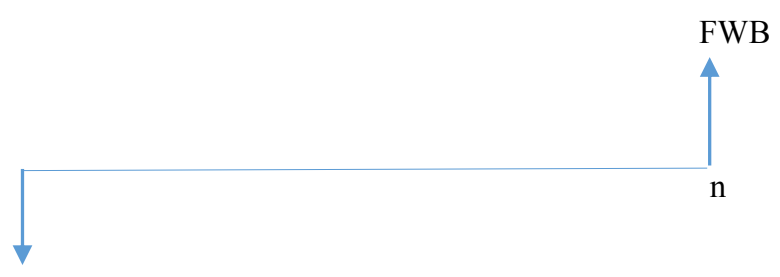

PWC

We define the ERR as the interest rate that balances the cash flow, that is:

$(1+\mathrm{ERR})^{\mathrm{n}} \mathrm{PWC}=\mathrm{FWB}$. Solving for the ERR, we get:

$\mathrm{ERR}=(\mathrm{FWB} / \mathrm{FWC})^{1 / \mathrm{n}}-1$.

A more informative formula can be obtained as follows: Let $r$ be the benefit cost ratio, then $\mathrm{FWB}=\mathrm{PWB}(1+\mathrm{MARR})^{\mathrm{n}} \Rightarrow \mathrm{ERR}=(1+\mathrm{MARR})$ $\mathrm{r}^{1 / \mathrm{n}}-1$.

\section{Some mathematical properties of the ERR}

Let $\mathrm{r}^{1 / \mathrm{n}=} \mathrm{x}$, and MARR $=\mathrm{a}$, then $\mathrm{ERR}=(1+\mathrm{a}) \mathrm{x}$;

1. Setting ERR $>$ MARR $\Rightarrow(1+a) x>1+a \Rightarrow x>1 \Rightarrow r>1 \Rightarrow P W B /$
PWC $>1$

Which implies that the net present worth $>0$,

2. Setting $E R R=M A R R \Rightarrow x=1 \Rightarrow r=1$, therefore $P W B=P W C$, and the net worth is zero.

3. Setting $\mathrm{ERR}<\mathrm{MARR} \Rightarrow \mathrm{x}<1 \Rightarrow \mathrm{PWB}<\mathrm{PWC}$, and therefore the net present worth is negative.

From the above, we can state the following criteria for the attractiveness of the investment which conform with the present worth method of the economic analysis:

- If ERR >MARR, the investment is attractive.

- $\quad$ If $E R R<M A R R$, the investment is not attractive.

4. Setting ERR $<0 \Rightarrow \mathrm{x}<1 /(1+\mathrm{a}) \Rightarrow \mathrm{r}^{1 / \mathrm{n}}<1 /(1+\mathrm{a}) \Rightarrow \mathrm{r}<(1 / 1+\mathrm{a})^{\mathrm{n}}$, so if the benefit-cost ratio $r<(1 / 1+M A R R)^{n}$, then the ERR is negative.

\section{Variability of the ERR in terms of the MARR}

Let MARR $=i$, where $i>0$. Let $B(i)=b_{1}(1+i)^{-1}+b_{2}(1+i)^{-2}+\ldots+b_{n}(1+i)^{-n}$, and,

$C(i)=c_{0}+c_{1}(1+i)^{-1}+c_{2}(1+i)^{-2}+\ldots .+c_{n}(1+i)^{-n}$, there are PWB and PWC evaluated at the discount rate $\mathrm{i}$.

Then the ERR function of the variable I, is: $\operatorname{ERR}(\mathrm{i})=(1+\mathrm{i})(\mathrm{B}(\mathrm{i}) /$ $\mathrm{C}(\mathrm{i}))^{1 / \mathrm{n}}-1$.

Now ERR $(0)>0$, if $\mathrm{r}>1$, and $<0$ ir $\mathrm{r}>1$.

$\lim _{\mathrm{i} \rightarrow 0} \operatorname{ERR}=\left(\frac{\sum \mathrm{bj}}{\sum \mathrm{cj}}\right)^{1 / \mathrm{n}}-1$

It follows that:

Limit $_{\mathrm{i} \rightarrow 0}$ ERR $>0$, if $\left(\frac{\sum \mathrm{bj}}{\sum \mathrm{cj}}\right)>1$.

And,

Limit $_{\mathrm{i} \rightarrow 0} \mathrm{ERR}<0$, if $\left(\frac{\sum \mathrm{bj}}{\sum \mathrm{cj}}\right)<1$.

Now $\underset{i \rightarrow \infty}{\operatorname{limit}} \operatorname{ERR}=\infty$

And $\lim _{\mathrm{i} \rightarrow \infty}\left(\frac{\mathrm{ERR}}{\mathrm{i}}\right)=0$, so the graph of the ERR function has an asymptotic direction with a zero slope (tends to be flat).

\section{Some possible graphs of the ERR function}
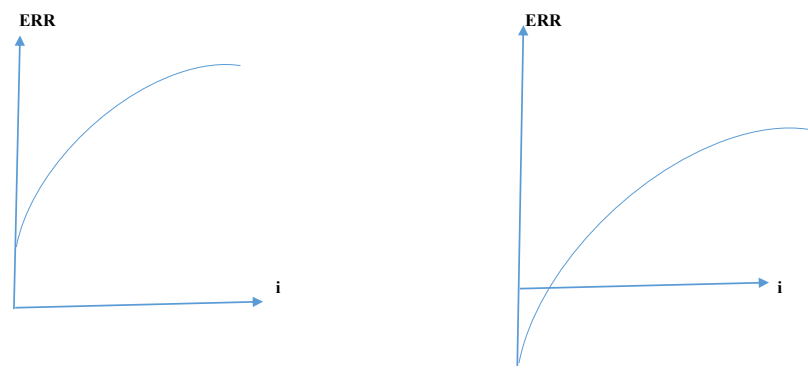

\section{Relationship between the ERR and the IRR}

The relationship between the ERR and the IRR will be obvious in the following theorem.

Theorem: If the investment has a unique IRR value, that is the equation, 
NPW (i) $=0$, has a unique positive root $=I R R$, and MARR $<$ IRR, then,

$M A R R<E R R \leq I R R$

Proof: for $\mathrm{i}<\mathrm{MARR}$, we have NPW (i) $>0$.

And since $M A R R<I R R$, then, IRR.

$\mathrm{Npw}(\mathrm{MARR})>0 \Rightarrow \mathrm{r}>1 \Rightarrow$ and $\mathrm{ERR}>\mathrm{MARR} \Rightarrow \mathrm{MARR}<\mathrm{ER} \leq \mathrm{R}$

MARR ERR IRR

Equality between the ERR and the IRR occurs for each cash flow with only two flows: $\mathrm{C}_{0}$ and $\mathrm{b}_{\mathrm{n}}$.

This is the case of an investment with an initial cost and all the return at the end of the useful life $[14,15]$.

To establish the equality, we have;

$\mathrm{EWB}=\mathrm{b}_{\mathrm{n}}$ and $\mathrm{PWC}=\mathrm{C}_{0}$

$E R R=\left(\frac{\mathrm{EWB}}{\mathrm{C} 0}\right)^{1 / n}-1=\left(\frac{\mathrm{bn}}{\mathrm{C} 0}\right)^{1 / n}-1$

On the other hand, $P W B=b_{n}(1+I R R)^{-n}$

but $b_{n}(1+I R R)^{-n}=C_{0}$

$(1+I R R) n=\frac{\mathrm{bn}}{\mathrm{C} 0}$

$\operatorname{IRR}=\left(\frac{\mathrm{bn}}{\mathrm{C} 0}\right)^{1 / n}-1$

So IRR=ERR

\section{The ERR and incremental analysis: Case of two investments}

As we pointed out before, that the ERR method can be used as a legitimate economic analysis method applied to a single revenue investment. Now in case of two mutually exclusive investments, incremental ERR is also applicable, but with the following assumptions to hold for the investment we call them $\mathrm{I}_{1}$ and $\mathrm{I}_{2}$.

1. The two investments have the same analysis period

2. $\mathrm{FWB}_{2}>\mathrm{FWB}_{1}$

3. $\mathrm{PWC}_{2}>\mathrm{PWC}_{1}$

4. Both have ERR $\geq$ MARR.

We define $\Delta E R R=\left(\frac{\mathrm{FWB} 2-\mathrm{FWB} 1}{\mathrm{PWC} 2-\mathrm{PWC1}}\right)^{1 / n}-1$

Now if $f \triangle E R R \geq M A R R, \mathrm{I}_{2}$ is preferred to $\mathrm{I}_{1}$; otherwise, $\mathrm{I}_{1}$ is preferred to $\mathrm{I}_{2}$.
Examples on how to employ the ERR method in economic analysis

Example 1 (case of a single revenue investment): Consider an investment of $\$ 1,000,000$ with annual costs of $\$ 100,000$ and annual returns of $\$ 350,000$ for the next 10 years, and suppose that the MARR is $10 \%$ per year.

$\mathrm{FWB}=350,000(1.1)^{10}=\$ 5,578,090$,

$\mathrm{PWC}=100,000(\mathrm{P} / \mathrm{A}, 10 \%, 10)+1,000,000=\$ 1,614,460$,

$E R R=\left(\frac{5,578,090}{1,614,460}\right)^{1 / 10}-1=13 \%$,

$13 \%>$ MARR $\Rightarrow$ investment is attractive.

Example 2 (Incremental ERR for two exclusive investments): Let the MARR be $10 \%$ a year.

$\mathrm{FWB}_{1=} 40,000(\mathrm{~F} / \mathrm{P}, 10 \%, 5)=\$ 244,204$

$\mathrm{PWC}_{1=} 100,000+8,000(\mathrm{P} / \mathrm{A}, 10 \%, 5)=\$ 130,326$

$E R R_{1}=\left(\frac{244,204}{130,326}\right)^{1 / 5}-1=13.38 \%>M A R R$

$\mathrm{FWB}_{2=} 35,000(\mathrm{~F} / \mathrm{P}, 10 \%, 5)=\$ 213,679$

$\mathrm{PWC}_{2=} 80,000+1000(\mathrm{P} / \mathrm{A}, 10 \%, 5)=\$ 102,745$

$E R R_{2}=\left(\frac{213,679}{102,745}\right)^{1 / 5}-1=15.77 \%>M A R R$,

$\mathrm{FWB}_{1}>\mathrm{FWB}_{2}$

$\mathrm{PWC}_{1}>\mathrm{PWC}_{2}$

So, we can apply incremental ERR (Table 1).

Now $\Rightarrow$ We select $I_{2}$.

\section{Case of many mutually exclusive investments}

We shall consider " $k$ " exclusive investments: $I_{1}, I_{2}, \ldots, I_{k}$, and assume that the conditions for the applicability of the incremental ERR analysis for two investments hold for two successive pains of the arranged according to increasing PWC and FWB. It is noteworthy here to state that condition " 4 " for the investments $\mathrm{C}$ can be ignored.

Now applying systematic elimination will yield one finally selected investment among the " $k$ " investments;

For this finally selected investment, we calculate its ERR and compare it to the MARR. Then if the ERR $\geq$ MARR, our final investment is the most attractive otherwise, none is attractive [16-18].

The following example shall illustrate the method:

Example 3

$\mathrm{FWB}_{1}=\$ 763,137$

$\mathrm{PWC}_{1}=\$ 500,000$

$\mathrm{FWB}_{2}=\$ 793,663$

\begin{tabular}{|l|c|c|}
\hline & $\mathbf{I}_{1}$ & $\mathbf{I}_{2}$ \\
\hline Initial cost & $\$ 100,000$ & $\$ 80,000$ \\
\hline Annual costs & $\$ 8,000$ & $\$ 6,000$ \\
\hline Annual benefits & $\$ 40,000$ & $\$ 35,000$ \\
\hline Useful life & 5 years & 5 years \\
\hline
\end{tabular}

Table 1: Consider the two mutually exclusive investments. 
$\mathrm{PWC}_{2}=\$ 530,000$

$\mathrm{FWB}_{3}=\$ 824,188$

$\mathrm{PWC}_{3}=\$ 560,000$

The arrangement is as the investments are: $\mathrm{I}_{1} \mathrm{I}_{2}, \mathrm{I}_{3}$.

Now we consider the incremental investment: $\mathrm{I}_{2}-\mathrm{I}_{1}$,

$\Delta E R R=\left(\frac{793,663-763,137}{30,000}\right)^{1 / 5}-1=0.34 \%$

$\Rightarrow$ Select $\mathrm{I}_{1}$ and remove $\mathrm{I}_{2}$.

Now we consider the incremental investment: $\mathrm{I}_{3}-\mathrm{I}_{1}$,

$\Delta E R R=\left(\frac{824,188-763,137}{10,000}\right)^{1 / 5}-1=0.3 \%$,

$\Rightarrow$ Select $\mathrm{I}_{1}$

Now we complete the ERR of $I_{1}$.

$E R R \approx(1+$ MARR $)\left(1+\frac{E(F W B)}{\mathrm{Co}}\right)^{-\bar{n}}-1$

So, none of the investments is attractive (Table 2).

\section{The ERR in the case of random cash flows}

When the cash flow stream of the investment is random, it is very difficult technically to find the probability distribution of the ERR. In this case, simulation will be used to study the properties of the distribution though the data obtained from the simulated samples. The natural criteria for the assessment of the economic worth will use only the expected value of the ERR as follows

If expected $E R R \geq M A R R$, accept

If expected $\mathrm{ERR}<\mathrm{MARR}$, reject.

An approximation to the expected value of the ERR may be found for there investment where the down flow consists only of a single flow at the origin Co and the positive flows are independent and identically distributed with a given probability distribution. The approximation formula is:

Expected $E R R \approx(1+\mathrm{MARR})\left(1+\frac{\mathrm{E}(\mathrm{FWB})}{\mathrm{Co}}\right)^{\frac{1}{n}}-1$

In what follows, we shall present investments with four possible distribution of the positive cash flow.

Example 1: Consider the investment with $\mathrm{Co}=10,000 \$$, a duration time of 7 years and the positive cash flow in uniformly distributed over the interval. $(\$ 1500, \$ 2000)$. The MARR is $10 \%$ a year.

The simulation gives an expected ERR value of $13.35 \%$ and has the estimating formula, it is $13.9 \%$. In both cases it is bigger than $10 \%$, so the investment is attractive.

Example 2: The initial investment is $\$ 10,000$. The duration time is 8 years. The positive cash flow is normally distributed with a mean of $\$ 1100$ and standard deviation of $\$ 100$. The MARR is $10 \%$ simulation

\begin{tabular}{|l|c|c|c|}
\hline & $\mathbf{I}_{1}$ & $\mathbf{I}_{2}$ & $\mathbf{I}_{3}$ \\
\hline Initial cost & $\$ 500,000$ & $\$ 530,000$ & $\$ 560,000$ \\
\hline Annual benefits & $\$ 125,000$ & $\$ 130,000$ & $\$ 135,000$ \\
\hline Useful life & 5 years & 5 years & 5 years \\
\hline
\end{tabular}

Table 2: Consider the three exclusive investments. gives the expected ERR is $12.35 \%$ and the estimating formula gives $13.2 \%$, Both are bigger than $10 \%$, so the investment is attractive.

Example 3: The initial investment is $\$ 12,000$. The duration time is 10 years. The positive cash flow is exponentially distributed with a mean of $\$ 1000$. The MARR is $10 \%$.

Simulation gives an expected ERR of $12.85 \%$, while the estimating formula gives $13.13 \%$, both are bigger than $10 \%$ so the investment is attractive.

Example 4: The initial investment is $\$ 15,000$. The duration time is 9 years. The positive cash flow has a systematic triangular distribution over the interval ( $\$ 800, \$ 1400)$. The MARR is $10 \%$. Simulation gives the expected ERR to be $9.7 \%$ and the estimating formula gives $9.96 \%$, both are less than $10 \%$ so the investment is not attractive.

The case of many mutually exclusive stochastic investments may be handled using simulation, but we have not sufficiently and thoroughly explored the matter in order to develop a solid criteria for selecting the most attractive investment. That will be the topic of a fortune research hopefully.

\section{Conclusion}

In this paper, we highlighted the mathematical properties of the Economic Rate of Return. We also established a relationship between the ERR and the IRR and suggested a financial interpretation of the ERR. We proved that the ERR method can by utilized as an economic analysis method just like present worth, annual worth, the IRR and the benefit-cost ratio methods. We showed the advantage the ERR has over the IRR both in interpretation and application. We also tackled economic analysis using the ERR in case of stochastic cash flow, and came up with an approximation formula for the expected ERR. Future research can focus on economic decision based on the ERR in the case of many exclusive stochastic investments.

\section{References}

1. Sullivan WG, Wicks EM, Koelling CP (2009) Engineering Economy (14thedn), Prentice-Hall, p: 696

2. Hajdasinski MM (1993) Payback period as a measure of profitability and liquidity. The Engineering Economist 38: 177-191.

3. Bernhard RH (1962) Discount methods for expenditure evaluation clarification of their assumptions. The Journal of Industrial Engineering 18: 19-27.

4. Brigham EF, Kahl AL, Rentz WF, Gapenski LC (1994) Canadian Financial Management (4thedn), Toronto: Harcourt Brace \& Co.

5. Park CS (2010) Contemporary Engineering Economics (3rdedn), Prentice-Hall, New Jersey.

6. Newnan DG, Whittaker J, Eschenbach TG, Lavelle JP (2010) Engineering Economic Analysis, Engineering Press, (2ndCanadian edn).

7. Newnan DG (2004) Engineering Economic Analysis (6thedn), Engineering Press, San Jose, California.

8. Sullivan WG, Wicks EM, Luxhoj JT (2006) Engineering Economy (13thedn), Prentice-Hall, New Jersey.

9. Blank LT, Tarquin AJ (2005) Engineering Economy (5thedn), McGraw-Hill, New York.

10. Steiner HM (1992) Engineering Economic Principles (2ndedn), McGraw-Hill, New York, 1992

11. White JA, Case KE, Pratt DB, Agee MH (1998) Principles of Engineering, Economic Analysis, Wiley, New York.

12. Cannaday RE, Colwell PF, Paley H (1986) Relevant and Irrelevant Interna Rates of Return. Engineering Economist 32: 17-38. 
Citation: Asrawi F, Noueihed N (2017) A Rigorous Mathematical Approach to the Economic Rate of Return (ERR) and its Application to Economic Analysis. Ind Eng Manage 6: 227. doi:10.4172/2169-0316.1000227

Page 5 of 5

13. Thuesen GJ, Fabrycky WJ (2001) Engineering Economy (9thedn), PrenticeHall, Englewood Cliffs, New Jersey.

14. Hajdasinski MM (1997) Using heuristics to evaluate projects: The case of ranking projects by IRR. The Engineering Economist 42: 163-166.

15. Hajdasinski MM (1987) On relevant and irrelevant internal rates of return. The Engineering Economist 32: 347-353.
16. Hartman JC, Schafrick IC (2004) The Relevant Internal Rate of Return, Engineering Economist 49: 139-158.

17. Hazen GB (2003) A new Perspective on Multiple Internal Rates of Return. The Engineering Economist 48: 31-51.

18. White JA, Case KE, Pratt DB, Agee MH (1976) Rate of return: An explicit reinvestment rate approach. Proceedings of the 27th Annual Conference of the AllE, St. Louis, Missouri, pp: 47-53. 